\title{
Simulation of physical processes and environmental monitoring at training and research stands
}

\author{
Aydar Nasrulin ${ }^{1}{ }^{*}$, Bekmamat Khamdamov ${ }^{1}$, Tashmirza Yuldashev $^{2}$, Dilbar Ergasheva ${ }^{2}$, and \\ Eduard $\mathrm{Kan}^{3}$ \\ ${ }^{1}$ Tashkent State Technical University, Tashkent, Uzbekistan \\ ${ }^{2}$ Karshi Engineering and Economic Institute, Tashkent, Uzbekistan \\ ${ }^{3}$ Tashkent institute of irrigation and agricultural mechanization engineers, Tashkent, Uzbekistan
}

\begin{abstract}
In this article, we also consider the results of studying the problems and prospects for the use of educational and research stands of the Department of Hydropower and Hydraulics and information technologies to provide modelling of physical processes and environmental monitoring. This will improve the methodology for the education of energy engineers to implement the program of measures for the further development of energy and renewable energy in Uzbekistan. As an example of such an approach, we can consider as one interconnected System that combines the results of work:

- Examples of methods for creating a virtual stand based on digital maps for information support of environmental monitoring of hydraulic structures;

- An example of an experimental stand for research on the operation of structures made of reinforced soil;

- Examples of stands for the study of hydraulic processes - an example of the development of instruments for hydrometric support. Experimental stands are given. Methods for creating hydrostatic pressure and own weight of the dam. Conclusions and recommendations based on the results of experimental research on educational research stands.
\end{abstract}

\section{Introduction}

One of Uzbekistan's strategic tasks for scientists and government institutions is to determine the way to more efficient use of natural energy resources for the agricultural and energy sectors of the economy of Uzbekistan. Much depends on the training of energy personnel. Training energy personnel is currently one of the most pressing issues for Uzbekistan's entire national economy. Uzbekistan's power industry is the main basic industry that determines the development of the country's economy. There are 273 large and significant hydraulic engineering objects in Uzbekistan. Of these: 50 - reservoirs, 35 pumping stations, 31 - hydroelectric power plants, 60 - main canals, 24 - main collectors, 64 - hydroelectric facilities. To ensure irrigated agriculture in Uzbekistan, 46668 inter-farm

*Corresponding author: nasrulin@mail.ru 
and 175,000 on-farm hydraulic structures function. The management of water resources and their use for various purposes is carried out through hydraulic structures, hydroelectric power plants and pumping stations, efficiency and reliability, which depend largely on project development quality. For the project's successful development, it is required to analyze the initial data (relief, geology, hydrology, etc.). To know used the structures of structures, the possibilities of application and the technology of their construction to master the methods of calculating the selected facilities, to predict the consequences caused by their construction and operation.

Therefore, the use of geographic information systems for environmental monitoring and the modelling of physical processes by educational and research stands will help designers reconstruct and construct new GTS, HPP, and pumping stations. The operation of hydraulic structures of reservoir units at the local runoff solves two main tasks:

- To ensure the supply of water from the reservoir following the established consumption schedule;

- To maintain the construction of the unit in working order.

These tasks should be considered a single set of operational measures, thanks to which the unit of structures is operated for fish farming, water supply, water supply, hydropower, etc.

At present, choosing a rational option of reinforcement from the constructional and economic point of view is one of the main problems of projecting the units (such as dams, breast walls, etc.) made of reinforced soil. The researches carried out on the prismatic model of reinforced soil confirmed that change in the features could be resulted by changing the percentage of reinforcement and the scheme of distribution of the armature in the soil. In this respect, choosing the right reinforcement of the material (reinforcement percentage, placement, and others) would have a huge priority.

As it is known, facing the reinforced slope, fulfilling the function of preventing spilling of the slope is one of the constructional elements of reinforced soil that can influence the unit's feature [1-17 ]. Hence, to evaluate the feature of the units, it would be proper to carry out research to evaluate the impact of various facings on the features of the units.

A number of studies on defining the tense and deformed state of the reinforced soil were held. In these researches, the load is mainly applied by the stamps and other means on the surface of the researched model, which distorts the law of change in pressure from the intrinsic weight by height. The research, held by the method of centrifugal modelling, may allow the modelling of the intrinsic weight. However, limited sizes of these models, rubbing the material of the researched model on the cartridge or the carriage may negatively impact the results. Hence, modelling of intrinsic weight by the anchors of the volumetric model, in several cases, would show a much fuller picture of the behaviour of reinforced soil, though these methods have certain faults.

As it is noted in work, the stripes on the armature are not broken simultaneously. This phenomenon progresses but goes very quickly: first, the tensest stripe is broken, then as soon as the tensions are distributed, comes the next stripe and so on. Also, it is assumed that if reinforced elements of lower layers are much tenser, then the breakage occurs exactly in those layers. In this regard, the creation of such System may let monitor the sequence of breakages of reinforcing elements in the model being independent of each other.

\section{Materials and Methods}

This work is devoted to solving the following issues:

1. Possibility of using geoinformation systems and of research- experimental stands as visual material for students-power engineers during the educational process; 
2. Development and application of computerized databases, geographic information systems and integrated models for environmental monitoring of hydroelectric power plants and pumping stations;

3. Potential and current use of models of physical processes at stands for research purposes. To study hydraulic processes, create experimental stands for dam stability, develop hydrometric support.

4. Creation of recommendations and methodological support based on the results obtained in the development of criteria for the safe operation of hydraulic structures, hydroelectric power plants, pumping stations.

\section{Results and Discussion}

During researches on blocks following problems was being solved:

\subsection{Hydroecological monitoring - virtual stand}

The method of hydroecological monitoring developed at the Department of Hydropower and Hydraulics is proposed as a virtual stand [18-24]. Digital mapping and geographic analysis are not entirely new. However, these technologies provide a new, more modern, more efficient, convenient and quick approach to analysing problems and solving problems facing humanity in general, and a specific organization or group of people, in particular. An analysis was carried out based on the information received on the chemical composition, technological schemes and tables of hydraulic and hydropower structures in Uzbekistan. For example, Figure 1 shows the use of geoinformation technologies for the ecological analysis of the Tuyabuguz reservoir.

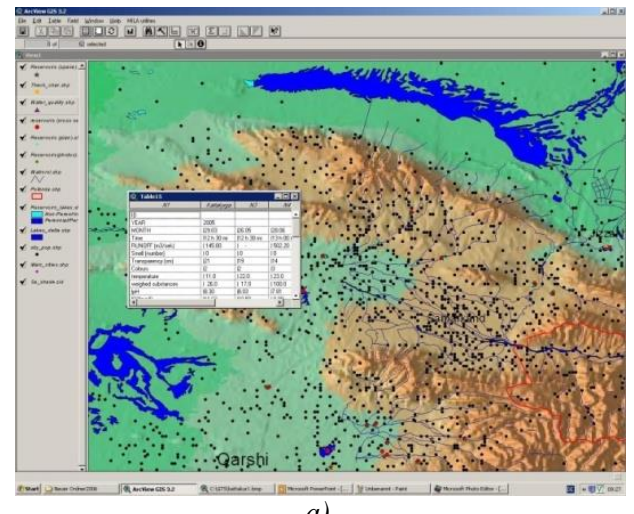

a)

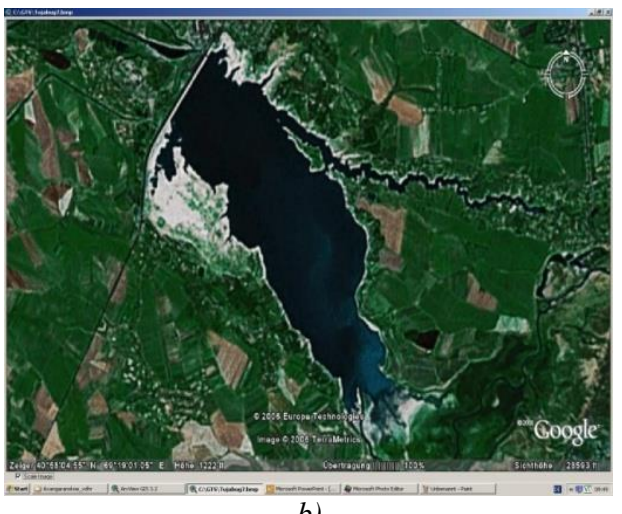

b)

Fig. 1. a) Table of the chemical composition of the Tuyabuguz reservoir, information can be obtained in two versions: 1) in the form of histograms; 2) in the form of tabular data, such as files in dBASE format; b) satellite image of the reservoir configuration from Google. The image can be used to determine ecologically sensitive areas, the direction of water flows depending on the terrain. With the help of digital maps, you can take into account the landscape and terrain, slopes, water discharge, seasonal floods and low water, select the optimal construction sites, strengthen mudflow-prone areas, predict landslides and landslides, and most importantly the number of settlements upstream that can pollute rivers with plastic and other rubbish.

\subsection{Hydraulic stands}

Training and research stands were developed (Figure 2) to study hydraulic processes. 


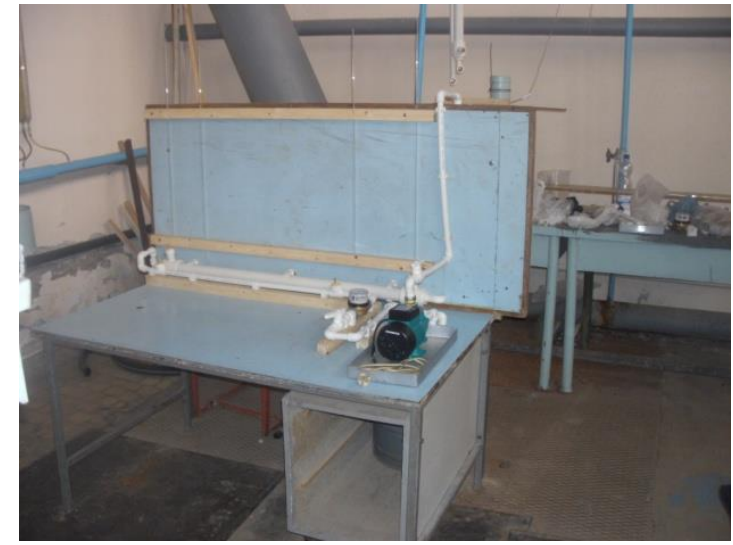

Fig. 2. Photos of the laboratory stand installation the stand is made in floor version.

The stand includes a table; piezometer shield; flow meter, intake manifold; piezometers 4; pressure pipelines; two tanks at different levels, pump with a built-in check valve. Two pipelines are fixed on the table surface, one $40 \mathrm{~mm}$, the second $105 \mathrm{~cm}$.

Description of the test bench for testing parallel and serial operation of pumps: the stand consists of 2 pumps of the company CONTE, model QB 60, connected in parallel, a connected tank, having the necessary measuring instruments and control valves. Details of the laboratory bench structure.

The main design details of the laboratory stand include the following (Figure 3):

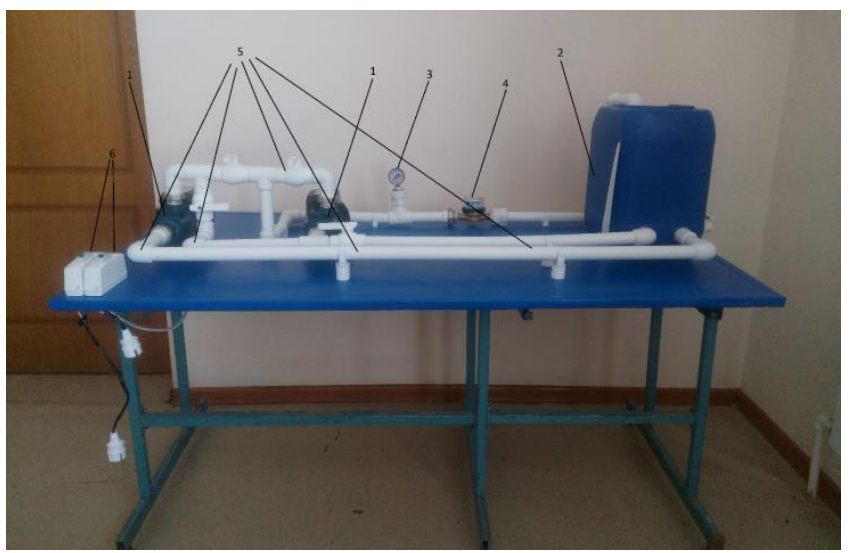

Fig. 3. General view of the laboratory stand

1. Centrifugal pumps

2. Tank

3. Pressure gauge

4. Flow meter

5. Plastic pipes (pipes, fittings, tees, etc.)

6. Automata

\subsection{Hydrometric measurements}

For measuring water flow rates, it is proposed to develop and create an experimental sample of a bladeless water velocity meter developed in the laboratory of hydrometry and metrology NIIIVP at TIIM [26]. 


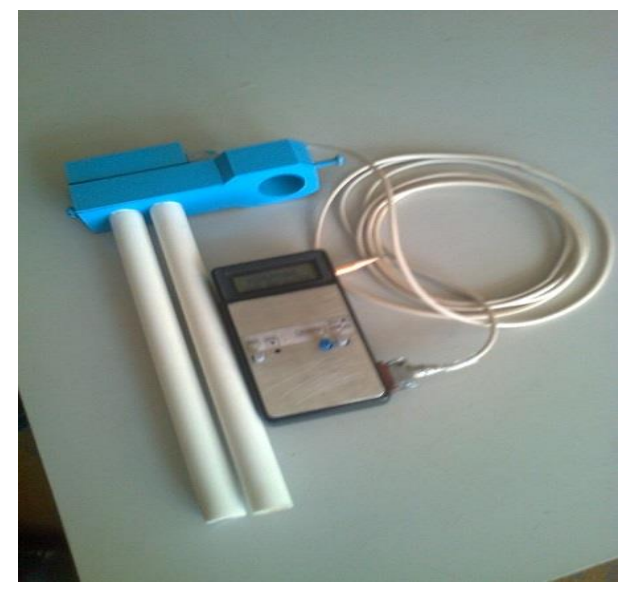

Fig. 4. Water speed meter

The device structurally consists of two parts: a sensor and an electronic signal processing unit, electrically connected to each other. The sensor is a converter of the water velocity into an electrical signal and is lowered to the controlled point of the water flow. The electronic unit processes the sensor signal according to the specified algorithm and displays the final result in digital form in units of speed.

\subsection{Description of the experimental stand of volumetric models of dams}

The experimental stand includes a welded metal construction with a firm bottom (modelling a full-size dam with a tight basis) and the side walls (Figure 5); the shape and size of the stand allow to place in it quite big volumetric models of dams made of reinforced soil. Side walls (8), imitating the sides of the cross-sections of the dam, are made of plexiglass width of which is $\mathrm{t}=10 \mathrm{~mm}$ and tightly attached into a metal frame. In order to create roughness, the surface of the plexiglass is processed with grinding paper. The upper part is made in the shape of a slope imitating the upper slope of a dam which is equal to $\mathrm{m}_{\mathrm{h}}=2.0$. The lower part is made of plexiglass in two options (continuous and cut vertically) $10 \mathrm{~mm}$ wide in the shape of a vertical breast wall.

Hydrostatic pressure is obtained by hydraulic pressing and thrusters (dia of the piston is $\mathrm{d} \Pi$ $=24 \mathrm{~mm}$ ) through metal stamps, the width of which is $d_{s h}=10 \mathrm{~mm}$. The stamps are made in terms of equal distribution of the hydrostatic pressure on the depth of upper reach. The thrusters are applied to each stamp's places of the gravity centres (4, Figure 5). Before the mounting thrusters, they are calibrated with a standard dynamometer. The calibrating is carried out with a load between $10 \mathrm{~atm}$. and $100 \mathrm{~atm}$. Further, the calibration curve is used while defining the load. 

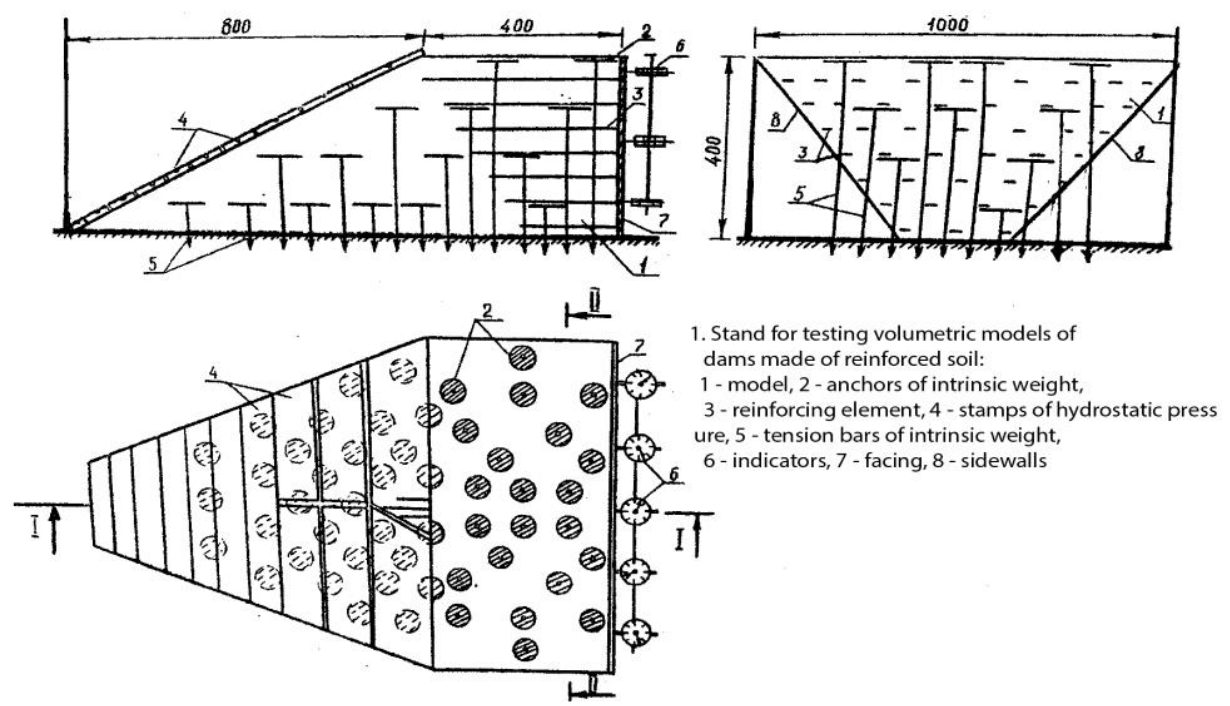

Fig. 5.

Intrinsic weight is obtained by hydraulic thrusters transmitting the pressure onto the tension bar through the loading plate. A flat metallic plate and hydraulic thrusters (dia of the picton is $d_{p}=58 \mathrm{~mm}$ ) are used to create the intrinsic weight. Before the experiments, the thrusters and the plate are calibrated. The calibration is done with the help of a standard dynamometer. Further, the calibration curve is used while defining the load of the intrinsic weight.

The intrinsic weight was obtained directly inside the model by the metal anchors diameter of $d_{a}=30,50,80 \mathrm{~mm}$, and $3 \mathrm{~mm}$. The anchors had holes in the middle. The diameter of was $d_{\text {Отв }}=3 \mathrm{~mm}$. The tension bars, made of fosta nylon, were attached to the anchors through the holes. The tension bars were passed through specially drilled holes on the bottom of the stand and connected to the loading plate by the hooks.

\section{Conclusions}

1. A virtual stand for hydro-ecological monitoring has been developed. Digital maps help to determine ecologically vulnerable zones, directions of water flows depending on the terrain; it is possible to take into account the landscape and terrain, slopes, water discharges, seasonal floods and low water, select the optimal construction sites, strengthen mudflow-prone areas, predict landslides and landslides, and most importantly the number of settlements upstream that could pollute rivers with plastic and other debris. In addition, using a digital map, you can learn access to the engineering and technical parameters of the dam; the student can see the dynamics over different years, how the reservoir is changing, and what opportunities are possible for modernizing the dam.

2. Stands for hydraulic tests have been developed

3. New methods of hydrometric support are proposed.

4. A stand has been developed for testing volumetric models of dams.

A loading device for modelling hydrostatic pressure and dead weight has been developed for it. The model manufacturing technology has been developed. Experimental studies were carried out, and the results obtained.

The results of the experimental researches have revealed that: 
- hydrostatic pressure does not significantly influence the features of the reinforced dam. This is why evaluating the features can be done by giving the load from the intrinsic weight. But hydrostatic pressure may lead to an extreme state which is described as the loss of strength of the dams to move as a whole in the form which is close to flat movement on low motional characteristics of the base;

- the researches have revealed that the increase in the length of the unit made of reinforced soil was effective compared to the reinforcement of extended elements on the lower part. Thus it must be taken into account that the reinforced elements of upper rows may slip in the soil due to a comparatively low volume of friction. Consequently, to improve the abilities, it would be effective to anchor the endings of the upper rows of reinforced elements into the soil;

- a smooth increase of the length of the reinforced elements by the height, compared to the step-by-step type, may give additional strength to the slope of the dam made of reinforced soil.

\section{References}

1 Bin L., Matthew S., Andrew B, and Kirsten A., Geographic information system algorithms to locate prospective sites for pumped hydro energy storage, Applied Energy 222 (15), pp 300-12, (2018)

2 McKinney C. and Savitsky A.G., EPIC modeling system guide - Water, salt and energy management problems (User Manual), Austin, Texas, USA, (2001).

3 Farrukh Shaazizov, et al, Development of the computerized decision-making support system for the prevention and revealing of dangerous zones of flooding, E3S Web of Conferences 97, FORM-2019, 05040 (2019)

4 Farrukh Shaazizov, Studies of turbulent flow characteristics of dividing open water streams//IPICSE 2020 IOP Conf. Series: Materials Science and Engineering 1030(012141) IOP Publishing doi:10.1088/1757-899X/1030/1/012141, (2021)

5 Farrukh Shaazizov, et al, System for ensuring the detection and elimination of fires in the building of the hydroelectric power station // IPICSE 2020 IOP Conf. Series: Materials Science and Engineering 1030 (012142) IOP Publishing doi:10.1088/1757899X/1030/1/012142, (2021)

6 N.C.Consoli, J.P.Montardo, P.D.M. Prietto, and G.S. Pasa, Engineering behavior of a sand reinforced with plastic waste." Journal of Geotechnical and Geoenvironmental Engineering, ASCE, 128(6), pp. 462-472. (2002).

7 M.Gosavi, K.A.Patil, S.Mittal and S.Saran, Improvement of properties of black cotton soil subgrade through synthetic reinforcement, Journal of the Institution of Engineers (India), 84, pp. 257-262. (2004).

8 P.K.Gupta, S. Saran and R.K. Mittal, Behaviour of fiber reinforced sand in different test conditions, Indian Geotechnical Journal, 36(3), pp. 272-282, (2006).

9 C.S.Heineck, N.C. Consoli and M.R. Coop, Effect of microreinforcement of soils from very small to large shear strains, Journal of Geotechnical and Geoenvironmental Engineering, ASCE, 127(3), pp. 258-268, (2005).

10 R. M. Koerner, Designing with geosynthetics, 5th edition, Prentice Hall, New Jersey, USA, (2005).

11 P. Kumar and S.P. Singh, Fibre-reinforced fly ash subbases in rural roads, Journal of Transportation Engineering, ASCE, 134(4), pp. 171-180, (2008).

12 R.L. Michalowski and J. Cermak, Triaxial compression of sand reinforced with fibers, Journal of Geotechnical and Geoenvironmental Engineering, ASCE, 129(2), pp. 125135, (2003).

13 M.I.M. Pinto, Reply to the discussion of Applications of geosynthetics for soil 
reinforcement by M.I.M. Pinto, Ground Improvement, 7(2), 2003, pp. 61-72 by S.K. Shukla, Ground Improvement, UK, 8, pp. 180-181, (2004)

14 S.K. Shukla and J.-H. Yin, Fundamentals of Geosynthetic Engineering, Taylor and Francis, London. (2006).

15 O. Glovatskiy, T.Djavburiyev, Z,Urazmukhamedova, A Gazaryan, F.Akhmadov. Interconnection of influent channel and pumping station units, E3S Web of Conferences 97, FORM-2019, 05040, (2019).

16 O. Glovatsky, B. Hamdamov, F. Bekchanov and A. Saparov, Strengthening technology and modeling of dams from reinforced soil, IPICSE 2020 IOP Conf. Series: Materials Science and Engineering 1030(012155) IOP Publishing doi:10.1088/1757-899X/1030/1/012155, (2021).

17 T.Yetimoglu and O. Salbas, A study on shear strength of sands reinforced with randomly distributed discrete fibers, Geotextiles and Geomembranes, 21, pp.103-110, (2003).

18 F.Shaazizov, A.Badalov,. D. Shukurov, and. D.Yulchiev, Hydraulic elevator for cleaning sediment of a water outlet of a reservoir, in IOP Conference Series: Materials Science and Engineering, 883(1) doi: 10.1088/1757-899X/883/1/012018, (2020).

19 D.Bazarov, F. Shaazizov and, S. Erjigitov, Transfer of Amudarya flowing part to increase the supportability of the Uzbekistan southern regions, in IOP Conference Series: Materials Science and Engineering, 883(1), doi: 10.1088/1757899X/883/1/012068, (2020)

20 A Nasrulin and A.Khamzina, Use of a model based hydroecological monitoring for managing the Aral Sea Basin, Annual meeting of the American institute of Hydrology and Hydrogeology, Hydrologic Issues of the $21^{\text {st }}$ Century; Ecology, Environment and Human Health, San Francisco, California; pp. 69-70, (1999)

21 A. Nasrulin, Hydroecological monitoring of the Aral Sea Basin in the purpose of Ecological safety, Journal "Water resource", Russia, Moscow, 1, pp.109-113, (2000)

22 K.Dzhuraev, A.Nasrulin, F. Shadibekova and S. Kurbonov, Geoinformation systems at the selection of engineering infrastructure of pumped storage hydropower for the tuyamuyun complex, IOP Conference Series: Materials Science and Engineering 869 (042004) doi:10.1088/1757-899X/869/4/042004, (2020).

23 A.B.Nasrulin, E.Sh. Sibukaev, Hydroecological monitoring technique for the study of rivers in the South of Russia, University Science, Modern Science: Theoretical and Practical Aspects, Journal based on the materials of the XXI International Scientific and Practical Conference / Mineralnye Vody, 1 (9), pp. 45-50, (2020).

24 M. Mukhammadiev, et al, A complexly method of GIS technologies and optimization models used in the development of environmentally acceptable modes of operation of hydraulic and hydropower facilities in Uzbekistan, Journal of Physics: Conference Series, Vol. 1425, (2020)

25 A. M. Pendzhiev, Je. H. Gurbanov, The basics of the geographic information system in the development of small hydropower Turkmenistan, Nauka. Mysl'. 3, (2015)

26 A.B. Nasrulin, U.R. Rasulov, Issues of developing new technologies for hydrometric support in order to solve hydrogeological, engineering-geological and hydroecological problems of Uzbekistan, In Mat. International scientific and technical conference dedicated to the 55th anniversary of the establishment of the Institute GIDROINGEO "Modern problems of hydrogeology, engineering geology, geoecology and ways to solve them, State Enterprise Institute GIDROINGEO, pp 325-327, (2015). 